\title{
Submission and Rebellion: Excessive Drinking of Women in Problematic Heterosexual Partner Relationships
}

\author{
Sylvia M. M. Lammers, M.S., * Gerard M. Schippers, Ph.D., \\ and Cees P. F. van der Staak, Ph.D.
}

Research Group on Addictive Behaviors, University of Nijmegen, Nijmegen, The Netherlands

\begin{abstract}
Functionality of alcohol use for coping with partner relationship problems was explored in a group of 45 alcohol-dependent women with semistructured interviews. Six functions were categorized, three of them referring to adjustment and three to opposition to the partner. Respondents who had started excessive drinking mainly in response to problems with the partner reported more partner-related functions than respondents for whom a problematic partner relationship was not an important factor in the development of excessive drinking. Respondents of the first group also reported other characteristics of their relationship, notably they said more often that their partner was dominant. It was concluded that for a subgroup of women with alcohol problems, alcohol use may be a way of coping with a situation of powerlessness toward the partner.
\end{abstract}

\footnotetext{
* To whom correspondence and requests for reprints should be addressed at Research Group on Addictive Behaviors, Department of Psychology, University of Nijmegen, P.O. Box 9104, 6500 HE Nijmegen, The Netheriands. Telephone: +31.80 .612668 . FAX: +31.80 .615594 .
} 
Key words. Alcohol; Women; Marital relationships; Functionality

\section{INTRODUCTION}

This paper reports on a qualitative study exploring functional relations between excessive alcohol consumption of women and problems they experience in the relationships with their partners. It is generally stated by problem drinkers that drinking is functional for coping with their personal problems; men more often refer to problems in the domain of work, and women more often mention difficulties with their partners (Curlee, 1970; Legnaro and Zill, 1983; Lindbeck, 1972; Lisansky, 1957; Vaglum and Vaglum, 1987; Vogt, 1987). Little is known about what the functions of alcohol use are for women with respect to partner relationship problems. Why do some women use alcohol for coping with these issues, and what is it that alcohol does for them?

A number of studies shed some light on this issue. A hypothesis emerged from laboratory research that marriages in which the male is alcoholic are characterized by a struggle for power (Schaap et al., 1991; Morgan, 1987). Alcohol use of the husband is imputed to be functional in such marriages because, when inebriated, he can behave negatively without being held responsible. A few studies of partners of alcoholic women suggested that power is also important in these marital relations. The partner was described as dominant and egocentric, and the marriage was characterized by a lack of emotional communication (Gomberg, 1974; Legnaro and Zill, 1983; Wood and Duffy, 1966). A qualitative study of alcoholic women (Vogt, 1987) also suggested that power struggles were going on in their marriages. According to Vogt, the women were always on the losing side, and could only be assertive and verbally aggressive toward their partner when intoxicated. This last observation was also made by Diamond and Wilsnack (1978) in a qualitative study of 10 "heavy" drinking lesbian women.

In a survey among Finnish and Estonian couples, Holmila (1987) found for husbands, but not for wives, a relationship between frequent drinking and marital dissatisfaction and quarrels. She suggested that men more than women use alcohol as a vehicle for expressing emotion and anger. However, this may only be true for physical expression of anger. In males, excessive alcohol use is associated with physically aggressive behavior inside and outside marriage (Halford and Osgarby, 1993); furthermore, aggressive arousal after drinking is expected more in males than in females (Brown et al., 1980). But regarding expectations of (verbal) expression of anger or assertiveness after drinking, no gender differences were observed in social or in problem drinkers (Brown et al., 1980). In a survey among United States women in 1981, Wilsnack et al. (1986) found "belligerence" as one of the problem consequences of "heavy" drinking in these women. 
After repeating the survey among United States women in 1986, Wilsnack (1991) drew attention to the issue of sexuality. Sexual "dysfunction" (see Note 1) was related to drinking level and predictive of the continuation of a drinking problem over time. Women with alcohol problems more often reported that they and their partners drank before or during sexual activity than other women. Moreover, women who reported alcohol problems and sexual dysfunction in 1981, and who divorced or separated between 1981 and 1986, were more likely to be free of alcohol problems in 1986 . Wilsnack proposed that perhaps alcohol is used to "treat" sexual problems.

This research on alcohol and (functionality of drinking in) marriage used very different populations of drinkers: self-referred subjects who met Diagnostic Research Criteria for Alcoholism (in laboratory research), subjects in treatment for alcohol problems (Gomberg et al., Wood and Duffy, Vogt et al.), subjects who were known as "heavy" drinkers in a gay community (Wilsnack and Diamond), social drinkers (Brown et al.), married young couples (Holmila), and problem drinkers (Wilsnack, 1991) in the general populations of different countries.

Although functionality of alcohol no doubt varies in different groups and cultures, the studies suggest that excessive alcohol use often is functional for the balance of power in intimate relationships, and that women may use alcohol in intimate relationships to express anger and dissatisfaction and to function sexually. Functionality of drinking has, however, not been operationalized explicitly in this previous research.

In the present study, functions of alcohol use were defined as effects of alcohol, as they can be observed in reports of drinking experiences, that are positively evaluated by the user or that have positive aspects for him or her. According to social learning theory, functions play a role in the onset and maintenance of excessive drinking (Orford, 1985). Elsewhere (Lammers et al., in press) we made a distinction between "direct" and "indirect" functions. Direct functions refer to the psychotropic effects of alcohol: effects on behavior and experience experienced as immediate, such as drinking to suppress stress and undesired emotions or to enhance assertiveness. Indirect functions refer to the social and psychological significations of drinking. For example, a woman can drink excessively to acquire the image of someone who can hold her drink, without attaching importance to the psychotropic effects of alcohol.

In our study we compared women whose alcohol problems developed in response to a problematic partner relationship with women whose alcohol problems did not originate in such a context. We examined whether women of the first group reported other functions of drinking and characteristics of their partner and partner relationship than those reported by women of the second group. 


\section{METHOD}

\section{Respondents}

The respondents were 45 women, between 30 and 55 years old, dependent or having been dependent on alcohol according to the criteria of DSMIII-R (American Psychiatric Association, 1987). The respondents reacted to calls for collaboration in a study aimed at gaining more knowledge about alcohol problems in women. The calls were placed in diverse media, and letters were sent via three treatment institutions. Criteria for selection were having Dutch nationality and seeing oneself as having-or having had not more than four years ago-a serious drinking problem. Nineteen persons who reacted were not included for the following reasons: they did not meet criteria $(N=$ $8)$; they were aggressive, drunken, or confused at the first telephone contact $(N=4)$; they canceled the appointment $(N=2)$; or the interview was dismissed afterward for diverse reasons $(N=5)$ (see Note 2).

Table 1 shows demographic and drinking history characteristics of the subjects.

\section{Procedure}

Semistructured in-depth interviews were held with the respondents by the first author during the years 1988 and 1991. A topic list was used which covered life and drinking history. This list was constructed on the basis of a pilot study with female members of A.A. The respondents were particularly encouraged to talk about aspects of drinking that related to functionality, that is, the effects and meanings of alcohol use, how they evaluated effects, how others saw these effects, and whether, and how, these effects were related to coping with problems they experienced. Interviews lasted up to 3 hours. Two respondents were visited twice because the interviews could not be completed in 3 hours. A list was made of all functions of alcohol use occurring in the interviews. It was examined whether there was enough information on each function to decide if it was present or absent in the drinking history of each respondent. If the information was not adequate, questions on this function were formulated for a second interview. Second interviews were held in 1991/ 92 with 43 respondents. No subject refused. From two subjects who could not be traced, the interviews were kept in the study because they provided a satisfactory amount of information. After the second interview, all functions were coded by three coders as present or absent on the basis of the relevant fragments of the interviews. The coders were psychologists. Intercoder reliability turned out to be acceptable (Lammers et al., in press). 
Table 1.

Alcohol-Dependent Women. Demographic Drinking History and Help-Seeking Variables for Total Group and Subgroups

\begin{tabular}{cccccc}
\hline Total & & Group & & Group \\
group, & & $1,{ }^{\mathrm{a}}$ & & $2, \mathrm{~b}$ \\
$N=45$ & SD & $N=23$ & SD & $N=18$ & SD \\
\hline
\end{tabular}

a. Age and drinking history variables (years):

Mean age

Age at start of excessive drinking

Age of first alcohol-related problem

Age of first help for alcohol problem

Length of drinking history ${ }^{\circ}$

Years of problem drinking $f$

b. Level of education $(N)$ :

Low (elementary school)

Intermediate (secondary school)

High (higher professional school or some years of college)

Total

$\begin{array}{lllllc}42.6 & 6.2 & 44.5^{c} & 5.7 & 40.3^{d} & 6.5 \\ 25.2 & 8.2 & 26.6 & 7.6 & 22.8 & 9.2 \\ 28.4 & 9.0 & 30.3 & 7.3 & 24.8 & 10.9 \\ 36.2 & 7.2 & 38.1 & 7.3 & 34.3 & 7.2 \\ 16.8 & 6.4 & 16.8 & 7.2 & 16.7 & 10.9 \\ 13.3 & 6.0 & 12.2 & 6.1 & 14.7 & 5.9\end{array}$

c. Economic prosperity $(N)$ :

Low (social minimum)

Intermediate (from minimum to modal)

High (above modal)

Total

$\begin{array}{lll}16 & 5 & 9\end{array}$

$17 \quad 12 \quad 5$

$12 \quad 6 \quad 4$

$\begin{array}{lll}45 & 23 & 18\end{array}$

$15 \quad 5 \quad 7$

$20 \quad 11 \quad 8$

$\begin{array}{lll}10 & 7 & 3\end{array}$

$\begin{array}{lll}45 & 23 & 18\end{array}$

d. Environmental background $(N)$ :

Urban areas

Rural areas

No fixed abode

Total

$\begin{array}{lll}31 & 15 & 14\end{array}$

$13 \quad 7 \quad 4$

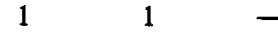

$45 \quad 23 \quad 18$

e. Marital status $(N)$ :

Married

Unmarried living together

Divorced and living alone

Never had a partner

Total

$21 \quad 13 \quad 8$

211

$\begin{array}{lll}19 & 9 & 9\end{array}$

$3-18$

$45 \quad 23 \quad 18$

f. Number of partners during drinking $(N)$ :

0

1

2

$>2$

Total

g. Number of children

h. Received treatment $(N)$ :

1. Intramural alcohol treatment

(only or with $2,3,4$ )

$4 \quad-\quad-$

$25 \quad 13 \quad 12$

$11 \quad 8 \quad 3$

$5 \quad 2 \quad 3$

$\begin{array}{lll}45 & 23 & 18\end{array}$

$\begin{array}{lll}1.9 & 2.5 & 1.2\end{array}$

$26 \quad 12 \quad 13$ 
Table 1. Continued

\begin{tabular}{|c|c|c|c|c|c|c|}
\hline & $\begin{array}{c}\text { Total } \\
\text { group, } \\
N=45\end{array}$ & SD & $\begin{array}{c}\text { Group } \\
1,{ }^{\mathrm{a}} \\
N=23\end{array}$ & SD & $\begin{array}{c}\text { Group } \\
2,{ }^{b} \\
N=18\end{array}$ & SD \\
\hline $\begin{array}{l}\text { 2. Ambulant alcohol treatment } \\
\text { (only or with } 3,4 \text { ) }\end{array}$ & 10 & 5 & 4 & & & \\
\hline 3. Psychosocial treatment & & & & & & \\
\hline (only or with 4 ) & 7 & 4 & 1 & & & \\
\hline 4. A.A. (only) & 1 & 1 & - & & & \\
\hline 5. No help at all & 1 & 1 & - & & & \\
\hline Total & 45 & 23 & 18 & & & \\
\hline \multicolumn{7}{|l|}{ i. Sexual abuse $(N): \mathrm{g}$} \\
\hline Before 16 years of age & 13 & 7 & 3 & & & \\
\hline Only after 16 years of age & 10 & 4 & 6 & & & \\
\hline
\end{tabular}

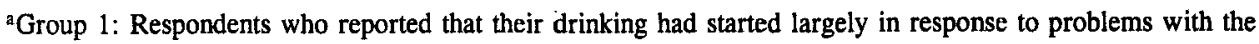
partner.

${ }^{b}$ Group 2: Respondents in whom either the drinking problem existed already before the relation with the partner, or in whom difficulties with the partner were not a major contributing factor.

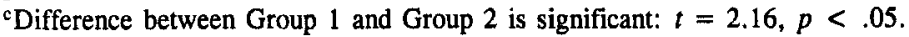

${ }^{\mathrm{d} D i f f e r e n c e}$ between Group 1 and Group 2 is significant: $t=3.69, p<.001$.

eNumber of years from first excessive drinking to time of interview or time of stopping excessive drinking. Excessive drinking was defined as beginning when subjects started to drink at least two glasses daily, or at least six glasses 2 days a week, or were drunk during 1 month several times.

Number of years from first alcohol-related problem to moment of interview or moment of stopping excessive drinking.

${ }^{\mathrm{g}}$ Sexual contacts or acts that the person is forced to commit or that the person feels he or she cannot refuse because of pressure or implicit threats by a more powerful person.

The topic list with respect to the partner(s) was as follows:

- Drinking behavior of the partner.

- Does (did) the respondent drink regularly with the partner?

- How does the respondent see the distribution of power between herself and the partner?

- Is (was) there any violence in the relationship?

- Does (did) the respondent hide her drinking from the partner?

- Are (were) there problems in the relationship? What does the respondent feel to be the major problem?

- Does (did) the partner in her opinion have a realistic image of the drinking behavior of the respondent?

- Does the respondent feel the partner has (had) advantages from her drinking? If so, which?

- Does (did) the partner stimulate seeking for help?

- What is (was) the attitude of the partner if the respondent actively seeks help? 


\section{Subgroups}

Only those 41 respondents who had at least one partner during the period of excessive drinking were included in the analyses. A "partner" was defined as the first person to whom the respondent had been married to, or with whom she had lived for at least 9 months, and who she considered to be (or have been) her partner (see Note 3). The respondents were classified in two groups. Group 1 consisted of the respondents who reported that their drinking had started largely in response to problems with the partner $(N=23)$. They were classified as such when they had a positive coding on both of the following questions: Did the drinking problem arise during the relationship? And: Does the respondent report difficulties with the partner as a major factor contributing to her drinking? Group $2(N=18)$ consisted of the respondents whose drinking problems already existed before the relationship with the partner, or who did not report difficulties with the partner as a major contributing factor to their drinking.

As Table 1 shows, respondents in Group 1 were older than in Group 2 and had more children. With respect to other demographic characteristics, received treatment and experience of sexual abuse, the two groups did not differ significantly.

\section{RESULTS}

\section{Partner Functions}

Elsewhere we reported how different functions of alcohol use were differentiated, coded, and placed in a taxonomic scheme (Lammers et al., in press). The division of functions in "direct" and "indirect" was one of the dimensions of this scheme. Of the 35 functions that were distinguished, six were related to problems with the partner. The frequencies of these six functions are given in Table 2. The first three functions can be considered as forms of adjustment to the partner, the last three as forms of resistance. We will define the functions and provide illustrations with quotes from the interviews (see Note 4).

Function 1 implies continuing to function in the relationship by virtue of the fact that alcohol soothes the emotions and cognitions related to the problems in the relationship.

One respondent said the only thing she did together with her husband was drinking a glass of sherry on Sunday afternoon. After her husband left her alone again, she had another sherry.

59.13 (see Note 5). I. On Sunday afternoon you had another sherry and then....

R. I didn't feel so alone any more. Or I resigned myself to sitting alone. I could have said how unsociable I thought he was or how 
Table 2.

Alcohol-Dependent Women. Partner-Related Functions in All Respondents with a Partner During Drinking History and in Subgroups 1 and $2^{\mathrm{a}}$

\begin{tabular}{|c|c|c|c|c|c|c|c|}
\hline \multirow[b]{2}{*}{ Partner-related functions } & \multicolumn{2}{|c|}{$\begin{array}{c}\text { Total group } \\
N=41 \\
\end{array}$} & \multicolumn{2}{|c|}{$\begin{array}{l}\text { Group 1, } \\
N=23 \\
\end{array}$} & \multicolumn{2}{|c|}{$\begin{array}{c}\text { Group 2, } \\
N=18 \\
\end{array}$} & \multirow{2}{*}{$\begin{array}{l}\text { Functional } \\
\text { Coefficients }^{\mathrm{b}}\end{array}$} \\
\hline & $N$ & $\%$ & $N$ & $\%$ & $N$ & $\%$ & \\
\hline $\begin{array}{l}\text { 1. Continuing to function in } \\
\text { relationship }\end{array}$ & 21 & 51 & 15 & 65 & 6 & $33^{\mathrm{c}}$ & .49 \\
\hline 2. Sexual adjustment to partner & 14 & 34 & 11 & 48 & 3 & $16^{\mathrm{d}}$ & .37 \\
\hline $\begin{array}{l}\text { 3. Drinking with partner to } \\
\text { communicate }\end{array}$ & 10 & 24 & 6 & 26 & 4 & 23 & \\
\hline $\begin{array}{l}\text { 4. Being able to oppose when } \\
\text { inebriated }\end{array}$ & 16 & 39 & 11 & 48 & 5 & 28 & \\
\hline $\begin{array}{l}\text { 5. Drinking as a signal or sign of } \\
\text { rebellion }\end{array}$ & 12 & 29 & 11 & 48 & 1 & $5^{e}$ & .70 \\
\hline $\begin{array}{l}\text { 6. Avoiding responsibilities by being } \\
\text { drunk } \\
\text { Mean total number of partner- } \\
\text { related functions }\end{array}$ & 1.98 & 17 & 2.52 & 17 & 1.28 & 17 & \\
\hline
\end{tabular}

${ }^{\mathrm{a}}$ For definitions of Groups 1 and 2, see Table 1.

${ }^{b}$ Standardized canonical discriminant Function Coefficients resulting from discriminant analysis of partnerrelated functions 1,2 , and 3 using the direct method.

${ }^{\mathrm{c}}$ Chi-square $=2.93, p<.10$.

${ }^{\mathrm{d}}$ Chi-square $=3.08, p<.10$.

${ }^{\mathrm{e}} \mathrm{Chi}$-square $=7.32, p<.01$.

${ }^{i} t$ value $=2.84, p<.01$.

I felt let down, but I could just as well say it to the chair, because he didn't listen anyway. And a sherry gives a little comfort then.

(later in the interview:) $59.35 \mathrm{R}$. In the first years, drinking made sure that I resigned myself to the situation, while actually I wanted to be recalcitrant. Because I drank, I continued to go on in the submissive pattern.

Function 2 refers to the adjustment specifically related to the sexual demands of the partner. If adjustment was limited to sexual demands, only this function and not Function 1 was positively coded.

16.11. I was strongly claimed by him, because he was the provider. And when I didn't want to make love to him, he accepted this for 1 week, but after that he claimed his rights. And for the sake of peace and quiet, well, o.k. I did submit myself once a week. And that 
evening I drank so I didn't have to feel it, all my disgust. Because it is only pretending then.

Function 3 is: Drinking with the partner to be able to communicate with him.

03.9. I was extremely tense, everyday in fact when he came home. I saw him coming and I thought: Oh my God, here he comes again. Later he expressed himself also: I felt like a visitor. And that was the truth. I could not be open with him. And then we drank something together and then something receded ... fell away. Then we could talk normally with each other again, very strange.

Function 4 implies resistance in a direct way. Alcohol gives the courage to express anger and frustration towards the partner and to assert oneself.

11.15. I. Did the alcohol for example have the effect that you dared to say more to your husband?

R. Surely.

I. What did you say then for example?

R. If he said: sit down here, I said: I will do what I want, or something like that. If we went to visit someone and he started to help me on or off with my coat, I said: You don't do that at home, so why would you do it here, for heaven's sake? And he couldn't stand that.

I. Was that something you didn't do normally, and only if you had been drinking?

R. Yes. In that period I realized that my husband dominated me. And I have tremendously braced myself against that.

Especially for women, drinking is readily seen as deviant. In Function 5 this deviance of drinking is deployed as a strategy to draw attention or as an act of resistance. In contrast to Functions 1 to 4 , this function is indirect, since psychotropic effects are not necessarily intended.

12.31. What I caught myself doing: I made a kind of game of it. "I'm doing something that you disapprove of." But then I was just so careless that it was found out nevertheless. "I do naughty things and then I got a dressing-down." Very peculiar. I had, for example, hidden a bottle in the piano. And I thought that on the verge of exciting: just imagine, he had to look in the piano! It is like passing with your car, while maybe it will be a narrow escape: the adrenaline is racing through your body. I wanted him somehow to discover it. It was a competition. It was a sheer cry for attention. You don't realize that you yourself are the loser. 
In Function 6 the direct physiological effect of alcohol is used more passively to resist or to make something clear to the partner. One does not say explicitly that one does not want things, but avoids them by being inebriated because then they are impossible. Things avoided vary from making dinner to having sex, and from accompanying the husband on visits to being mentally present for the partner.

79.35. I. What does or did the drunken bout mean for you?

R. That was when I drank tremendously. That was forgetting for a while, just not being there.

I. Was that the most important aspect?

R. Yes. No husband, no children. I am just not approachable then, so they cannot quarrel with you either.

\section{Partner Functions}

Table 2 shows the frequencies of partner functions and the total number of partner functions for Groups 1 and 2. Because of the explorative character of the study, a significance level of $p<.10$ or less (two-tailed) is mentioned.

Group 1 reported more partner functions than Group $2(p<.01)$. "Drinking signal or sign of rebellion" ( $p<.01)$, "drinking to continue functioning in the relationship" ( $p<.10)$, and "sexual adjustment to the partner" $(p<.10)$ were reported more often by Group 1. Discriminant analysis on these variables using the direct method of analysis gave one significant Discriminant Function (Wilks' lambda $=.67$; chi-square $=14.70 ; p<.01$ ).

Using the obtained classification functions, $67.5 \%$ of the respondents could be placed in the correct group (Table 3), which indicates that the functions of

Table 3.

Classification Results of Discriminant Analysis of Partner-Related Functions of Alcohol

\begin{tabular}{lccc}
\hline & & \multicolumn{2}{c}{ Predicted group membership } \\
\cline { 3 - 4 } Actual group $^{\mathrm{a}}$ & No. of cases & 1 & 2 \\
\hline Group 1 & 22 & 13 & 9 \\
& & $59.1 \%$ & $40.9 \%$ \\
Group 2 & 18 & 4 & 14 \\
& & $22.2 \%$ & $77.8 \%$
\end{tabular}

Percent of "grouped" cases correctly classified: $67.5 \%$

${ }^{\mathrm{a}}$ For definitions of Groups 1 and 2, see Table 1. 
alcohol relating to the partner had discriminating power, but that it was not very high. The last column in Table 2 shows the Function Coefficients; "drinking as a signal or sign of rebellion" made the largest contribution to the Discriminant Function.

\section{Variables Relating to the Partner and the Relationship}

Characteristics of the partner and the relationship as seen by the respondent can be seen in Table 4.

In Group 1, respondents saw the partner as being dominant more often. A most important problem was the reported lack of understanding from the partner. The partner in Group 1 had a realistic image of the drinking behavior of the respondent less often, and was seen to have more advantages from her drinking. However, the partner himself was not reported any more often as an excessive or problem drinker. Other differences point in the direction of further problems in the relationship, but are not significant.

Discriminant analyses of Variables 1, 5, 7, and 11 from Table 4 gave one significant Discriminant Function (Wilks' lambda $=.53$; chi-square $=23.49$; $p<.001$ ). On the basis of this, $82.9 \%$ of the respondents could be placed in the correct group (Table 5). Comparison of Tables 3 and 5 shows that the discriminating power of the characteristics of the relationship is larger than of the partner-related functions of alcohol use. Adding partner-related functions as variables in the discriminant analysis of Table 5 did not improve classification results. As is shown in the last column of Table 4, the largest contributions to the Discriminant Function were made by "lack of understanding" and "partner is dominant."

\section{DISCUSSION}

The present investigation was limited in that we used retrospective selfreported data and a relatively small sample of respondents. We see the results as hypotheses for further research. Differences were observed in functions of alcohol use between women who started excessive drinking largely as a response to a problematic (heterosexual) relationship and women for whom relationship problems were not an important factor in the development of excessive drinking. Alcohol consumption in the first group primarily seemed to be a means of adjustment: to keep going in the relationship by suppressing undesired emotions and to adjust sexually. On the other hand, alcohol enabled resistance: the first group used "alcoholic" behavior more often as a signal or a sign of rebellion toward the partner.

Respondents of the first group also reported specific characteristics of the relationship. Discriminant analysis showed that these characteristics were more 


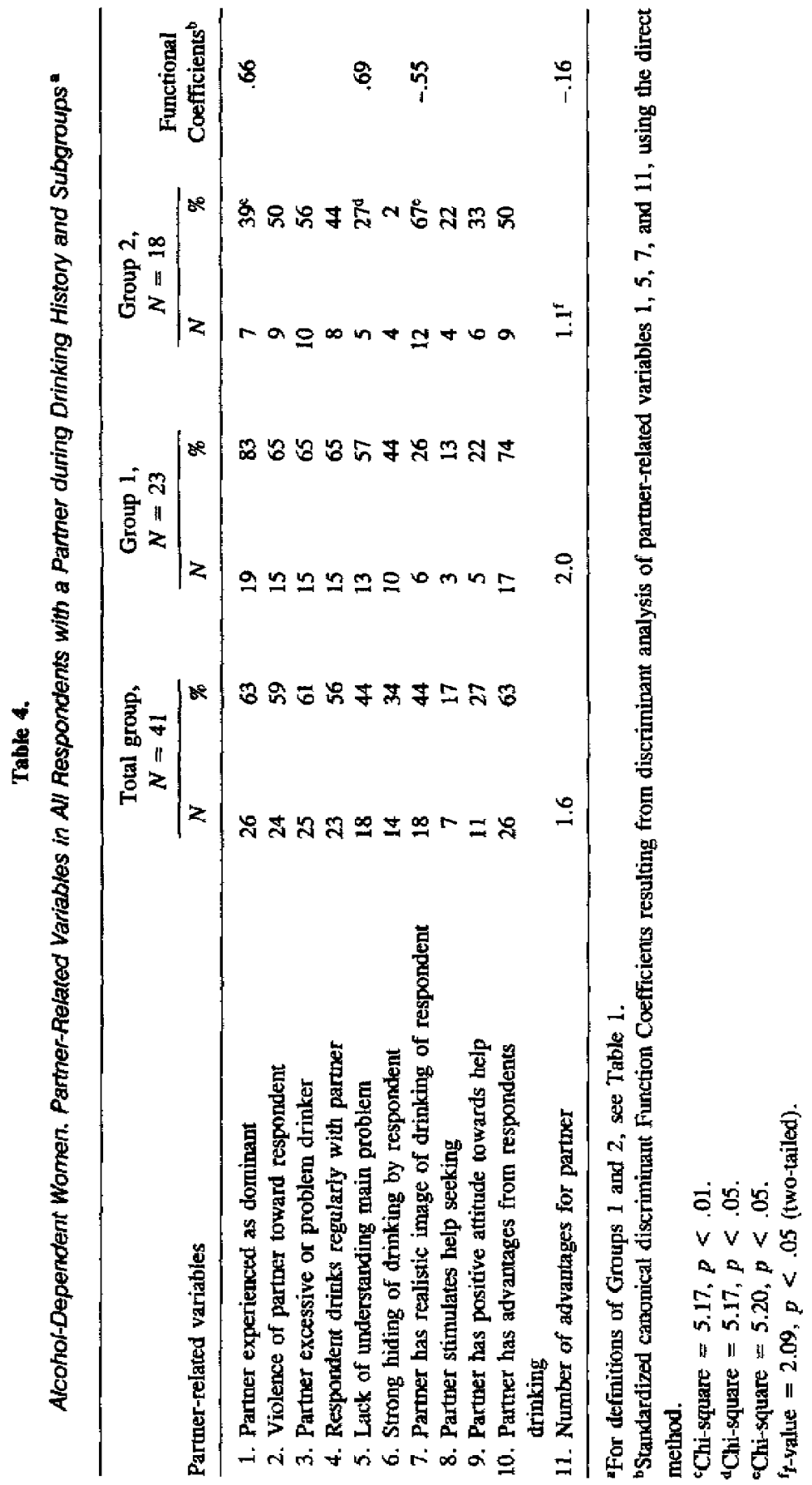


Table 5.

Classification Results of Discriminant Analysis of Partner-

Related Variables

\begin{tabular}{lccc}
\hline & & \multicolumn{2}{c}{ Predicted group membership } \\
\cline { 3 - 4 } Actual group & No. of cases & 1 & 2 \\
\hline Group 1 & 23 & 21 & 2 \\
\multirow{2}{*}{ Group 2 } & 18 & $91.3 \%$ & $8.7 \%$ \\
& & 5 & 13 \\
& & $27.8 \%$ & $72.2 \%$ \\
& Percent of "grouped" cases correctly classified: $82.9 \%$ \\
\hline
\end{tabular}

aFor definitions of Groups 1 and 2, see Table 1.

powerful in discriminating Groups 1 and 2 than the partner-related functions. Compared with Group 2, the partner was more often viewed as dominant, as not understanding the respondent, and furthermore as having less often a realistic image of her drinking behavior and as having a greater number of advantages from her drinking.

This pattern of functions and characteristics gives an indication of the kind of relationships in which women may develop a drinking problem. In the interviews the majority of respondents in the first group described their partner as controlling and as not giving the attention and understanding they needed. Some respondents had very high expectations of marriage and were extremely disappointed by the reality of it, but felt powerless in the face of this. Sexuality was frequently experienced as a disgusting obligation since there was no emotional bond with the partner and/or since sexual traumatization during childhood had made sexuality problematic. Drinking made it possible to submit and tolerate sexual intercourse. For this and other reasons, the partner was often felt by the respondent to profit from her drinking.

Sooner or later, however, submission turned to revolt in many women. Drinking profusely, being overtly drunk, and neglecting household responsibilities when drunk were described as ways of desperately seeking attention from the partner. These conspicuous behaviors were intended to provoke a response since the usual complaints and protests were ignored. Furthermore, a number of women said that, when inebriated, they started to express feelings of anger and disappointment toward their partner or to talk back to him, often after years of submission.

The results of this study suggest that for a subgroup of women, excessive alcohol use is a strategy to deal with a situation of experienced powerlessness toward their partner and to meet the demands of the marriage ideal of "har- 
monious inequality" (Komter, 1990). Studies into marriage relationships (Hochschild and Machung, 1989; Komter, 1985) have shown that women often resign themselves to the status quo because they do not want to endanger their marriage and do not expect a positive change anyway. Many women in this study seemed to use alcohol to be able to arrive at such a resignation.

Some results of this study are in line with and give a more detailed elaboration of findings of previous research. Alcohol use has been found to play an important role for sexual functioning in women with alcohol problems (Wilsnack, 1991). Our study suggests that this might be especially true for women who start drinking in connection with partner relationship problems. The effect of alcohol on sexual functioning was described in the interviews as the suppression of disgust and aversion so that the respondent could adjust to the partners wishes. A few women reported that alcohol use increased their own sexual pleasure (see Note 6).

Furthermore, the study supports the idea that power is an important issue in the partner relationships of alcohol-dependent women. It is striking that not only direct but also indirect effects of alcohol were used for resistance, such as using "alcoholic" behavior as a way of drawing attention. The importance of indirect, nonpsychotropic effects of alcohol is not as yet sufficiently acknowledged in the alcohol use/misuse research field.

Dominance of the partner and lack of emotional communication with the partner was also reported in other research. Our results suggest that these characteristics apply especially to women who start drinking as a response to relationship problems.

The study fosters some speculation about the consequences of the woman's drinking for the relationship. Adjustment and submission of the respondent with the help of alcohol often kept the harmony intact for the outside world. In fact, the partners grew apart more and more, however, because the husband resented the drinking of the wife and she reacted by secluding herself from him. Revolt from her side arose sometimes after a long period of drinking, induced nonproductive quarrels and conflicts, frequently ending in divorce.

Vogt (1987) concluded that problem-drinking women are on the losing side in their marriages. In the present study this seemed not always to be the case. Four respondents-with relatively mild alcohol problems--seemed to have gained some power by drinking. They used drinking intentionally and from the beginning to draw their partner's attention and to oppose him. Two of them provoked him to go into relationship therapy, with positive results. The other two women were more assertive after drinking and learned to manage this without alcohol.

The finding that the women in the first group attributed more advantages of their drinking to their partner raises the question whether these partners were codependent. This is one of the issues that should be studied in further research 
on the dynamics of alcohol use in partner relationships. With respect to treatment and prevention of alcohol problems, this study emphasizes the importance of the partner relationships of women who drink excessively. Drinking may be used by many of these women to cope with a situation of experienced powerlessness toward the partner. Preventive and therapeutic interventions can be aimed at learning more productive ways of dealing with this kind of problem.

\section{NOTES}

1. The term "dysfunction" suggests that the women didn't function well sexually, or rather, not according to certain norms. However, for example, "lack or low frequency of orgasm with a partner," one of the indicators of sexual dysfunction, can mean that it is not the woman but the partner or the couple that does not function well.

2. A more extensive discussion of the recruitment of respondents and other methodological issues of this project can be found in Lammers et al. (in press).

3. Partners referred to are male, unless indicated otherwise. Two respondents in Group 2 had female partners.

4. The quotes were minimally adjusted for readability.

5. The first number is the number of the respondent; the second number refers to the number of the quote from this respondent.

6. Increasing pleasure was coded as another function and is not reported here.

\section{REFERENCES}

AMERICAN PSYCHIATRIC ASSOCIATION (1987). Diagnostic and Statistical Manual, Version III, Revised. Washington, D.C.: American Psychiatric Association.

BROWN, S. A., GOLDMAN, M. S., INN, A., and ANDERSON, L. R. (1980). Expectations of reinforcement from alcohol: Their domain and relation to drinking patterns. $J$. Cons. Clin. Psychol. 48(4): 419-426.

CURLEE, J. (1970). Comparison of male and female patients at an alcoholism treatment center. J. Psychol. 74: 239-247.

DIAMOND, D. L., and WILSNACK, S. C. (1978). Alcohol use among lesbians: A descriptive study. J. Homosex. 4: 123-142.

GOMBERG, E. S. (1974). Women and alcoholism. In V. Franks and V. Burtle, (Eds.), Women in Therapy. New York: Brunner/Mazel.

HOCHSCHILD, A., and MACHUNG, A. (1989). The Second Shift. New York: Avon Books.

HALFORD, W. K., and OSGARBY, S. M. (1993) Alcohol abuse in clients presenting with marital problems. J. Fam. Psychol. 6: 245-254.

HOLMILA, M. (1987). Young families and alcohol use in Finland and the Soviet Union. Contemp. Drug Probl. pp. 649-672.

KOMTER, A. (1985). De macht van de vanzelfsprekenheid in de verhoudingen tussen de seksen (The Power of Self-Evidence in Gender Relations). Dissertation, University of Leiden, The Netherlands.

KOMTER, A. (1990). De macht van de dubbele moraal. Verschil en gelijkheid in de verhoudingen tussen de seksen (The Power of the Double Standard. Difference and Equality in Gender Relations). Amsterdam: Van Gennep.

LAMMERS, S. M. M., SCHIPPERS, G. M., and STAAK, C. P. F. VAN DER (in press). Psy- 
chological functions of drinking in alcohol dependent women: An exploration based on a dimensional framework. Addict. Res.

LEGNARO, A., and ZILL, G., (1983). Ein Verhalten das Männer Alkoholismus nennen: Alkoholkonsum in weiblicher Lebenszusammenhang (A behavior that men call alcoholism: Alcohol consumption in the life condition of women). In H. Berger, A. Legnaro, and K. Reuband (Eds)., Frauenalkoholismus: Enstehung, Abhängigkeit, Therapie (Alcoholism in Women: Development, Dependence, Therapy). Stuttgart: Kohlhammer.

LINDBECK, V. L. (1972). The women alcoholic. Int. J. Addict 7: 567-580.

LISANSKY, E. S. (1957). Alcoholism in women: Social and psychological concomitants: I. Social history data. Q. J. Stud. Alcohol 18: 588-623.

MORGAN, P. (1987). Women and alcohol: The disinhibition rhetoric in an analysis of domination. J. Psychoact. Drugs 19: 129-133.

ORFORD, J. (1985). Excessive Appetites: A Psychological View of Addictions. Chichester: Wiley.

SCHAAP, C. P. D. R., SCHELLEKENS, I., and SCHIPPERS, G. M. (1991). Alcohol and marital interaction: The relationship between male alcoholism, interaction characteristics and marital therapy. In G. M. Schippers, S. M. M. Lammers, and C. P. D. R. Schaap (Eds.), Contributions to the Psychology of Addictions. Lisse: Swets \& Zeitlinger.

VAGLUM, S., and VAGLUM, P. (1987). Partner relations and the development of alcoholism in female psychiatric patients. Acta Psychiatr. Scand. 76: 499-506.

VOGT, I. (1987). Idealtypische Lebensmuster alkoholabhängiger Frauen (Types of life patterns of alcoholic women). Suchtgefahren 33: 290-297.

WILSNACK, S. C. (1991) Sexuality and women's drinking. Findings from a U.S. national study. Alcohol Health Res. World 15: 147-150.

WILSNACK, R. W., WILSNACK, S. C., and KLASSEN, A. D. (1986). Antecedents and consequences of drinking and drinking problems in women: Patterns from a U.S. national study. Nebr. Symp. Motiv.

WOOD, H. P., and DUFFY, E. L. (1966). Psychological factors in alcoholic women. Am. J. Psychiatry 123: 341-345.

\section{THE AUTHORS}

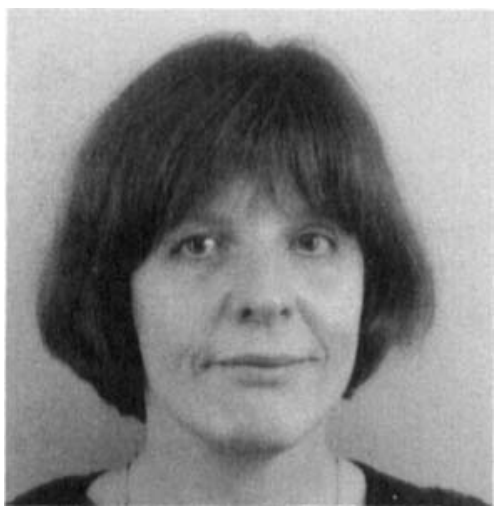

Sylvia M. M. Lammers, M.S., is a researcher and a lecturer at the Department of Clinical Psychology and the Centre of Women's Studies of the University of Nijmegen, The Netherlands. She is writing a dissertation about functionality of alcohol use for problem-drinking women. 


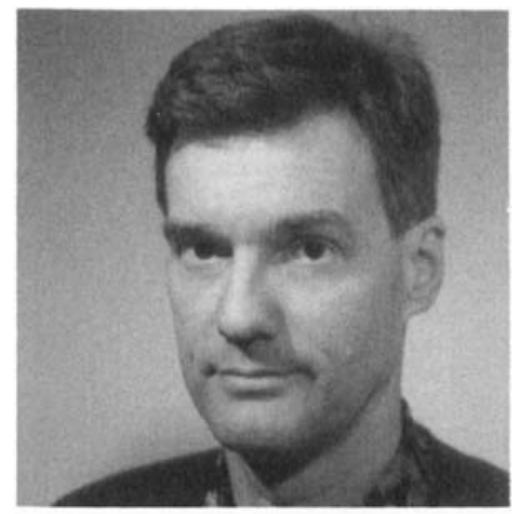

Gerard M. Schippers, Ph.D., is associate professor in the psychology of addictive behaviors. He is director of the University of Nijmegen Research Group on Addictive Behaviors (UNRAB).

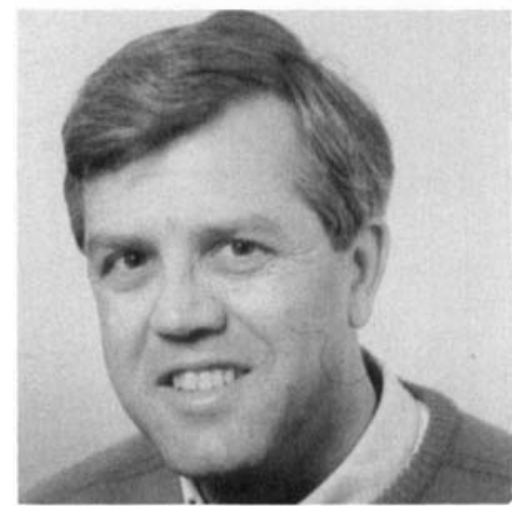

Cees P. F. van der Staak, Ph.D., is professor of Clinical Psychology, University of Nijmegen. 